Published by Al-Nahrain College of Medicine P-ISSN 1681-6579

E-ISSN 2224-4719

Email: iraqijms@colmed-alnahrain.edu.iq

http://www.colmed-alnahrain.edu.iq

http://www.iraqijms.net

Iraqi JMS 2019; Vol. 17(1)

\title{
Effects of Different Doses of Gamma Rays and Ascorbic Acid Concentration on Human RBCs for Conservation Purpose
}

\author{
Kharman A. Faraj ${ }^{1} P h D$, Samera H. Abdullah ${ }^{2} M S c$, Sameen F. Muhammad ${ }^{2} P h D$ \\ ${ }^{1}$ Dept. of Physics, College of Science, University of Sulaimani, Iraq, ${ }^{2}$ Dept. of Nursing, Technical Institute of Kirkuk, \\ Northern Technical University, Iraq
}

\begin{abstract}
Background Blood preservation and the development of sterile collection sets made possible the developments in blood components preparation, storage and transfusion that we have in today's blood banks and transfusion services.

Objective To investigate the effects of gamma irradiation, ascorbic acid and the combined effect of both on the lifespan of erythrocytes through determining red blood cells hemolysis for conserving it as long as possible without any change in erythrocytes biophysical properties.

Methods The blood was drawn from 10 healthy ( 5 males and 5 females) volunteers. Sample has been irradiated using $137 \mathrm{Cs}$ source. Different concentrations of ascorbic acid were used as an antioxidative agent for erythrocytes in blood suspension samples. A spectrometer was used for recording the data.

Results The results showed that $25 \%$ of RBCs hemolysis occurred after irradiation with 5 Gy of gamma ray during $5^{\text {th }}$ week of storage time while in un-irradiated sample $33.8 \%$ of RBCs hemolysis occurred during the $5^{\text {th }}$ week. $25 \%$ of RBCs hemolysis for $10 \mu \mathrm{M}$ of ascorbic acid concentration started after $7^{\text {th }}$ week while for control started after $4^{\text {th }}$ week. The minimum rates of RBCs hemolysis observed in the samples which pre-treated with (7 and 10) $\mu \mathrm{M}$ concentrations of ascorbic acid then irradiated with $1 \mathrm{~Gy}$.

Conclusion The results indicated that irradiation of human blood with a certain doses of gamma ray, treated with small concentration of ascorbic acid or both, the two factors together can protect the blood from hemolysis for a longer time and the minimum rate of red blood cells hemolysis was observed for $10 \mu \mathrm{M}$ ascorbic acid concentration then irradiation to $1 \mathrm{~Gy}$ of gamma ray.

Keywords Gamma ray, ascorbic acid, blood storage, red blood cells, oxidative damage

Citation Faraj KA, Abdullah SH, Muhammad SF. Effects of different doses of gamma rays and ascorbic acid concentration on human RBCs for conservation purpose. Iraqi JMS. 2019; 17(1): 50-56. doi: 10.22578/IJMS.17.1.8
\end{abstract}

List of abbreviations: ATP = Adenosine triphosphate, DPG= Biophosphoglyceric, GVHD = Graft-versus-host disease, $\mathrm{Hb}=$ Hemoglobin, $\mathrm{K}=$ Potassium, $\mathrm{Na}=$ Sodium, $\mathrm{OH}=$ Hydroxyl, RBCs $=$ Red blood cells, $\mathrm{SOD}=$ Superoxide dismutase

\section{Introduction}

There is a growing concern about the possible health effects associated with exposure to electromagnetic fields.

Due to the insufficient number of blood donors in the suitable time, the process of blood conservation has become a necessary and an inevitable process. The preserved red blood cells (RBCs) for clinical transfusions must meet minimum requirements to the stored blood to continue its metabolic functions and deplete the metabolites necessary to maintain RBCs viability and function.

It is so significant to recognize that RBCs undergo structural and morphological changes 
associated with Adenosine Triphosphate (ATP) depletion and oxidative damage of membrane lipids upon storage; such lesions are called storage lesions that depend on storage conditions, storage length and additives used in blood productions ${ }^{(1)}$. For this, the whole blood used for transfusion can be stored in blood bags at $4{ }^{\circ} \mathrm{C}$, and used within approximately one month to achieve its vital goal.

Mammalian RBCs do not have nucleus like other cells in the body, therefore during their circulation through capillaries they get deformed ${ }^{(2)}$. This deformation of RBCs is one of properties to maintain viability. If the deformation of cells is too large then the cells will get hemolysis easily. The cytoskeleton structures of the RBCs membranes responsible to restore its shape after deformation by the capillaries ${ }^{(2)}$. Exposure to ionizing radiation can kill some types of cells while modify others ${ }^{(3)}$. For checking the validity of stored blood has been investigated by (Marjani et al. 2007) and (Huyut et al. 2016). These authors investigated the malondialdhyde formation and antioxidant enzyme activity in stored blood ${ }^{(4,5)}$. Reactive oxygen metabolites and free radicals are generated normally in aerobic organisms. Membrane lipids are major targets for cellular damage of radical mediated lipid peroxidation. It is recognized that aerobic cells are primary protected from the free radical damage by endogenous antioxidants ${ }^{(6)}$. The effect of gamma radiation on the stored blood was investigated in several studies using wide range of doses. Moor and Ledoford (1985) who studied the effect of $40 \mathrm{~Gy}$ irradiation on the invitro storage properties of packed red cells (7), Anand et al. (1997) from zero to $50 \mathrm{~Gy}{ }^{(8)}$, and Brugnara and Churchill (1992) 2000 cGy ${ }^{(9)}$. The prevention of graft - versus - host disease (GVHD) is probably one of the major reasons for blood irradiation, and its use in susceptible patients has increased ${ }^{(10,11)}$.

Many studies; Britten (1999), Davey et al. (1992), Pribush et al. (1994) and Katz et al. (1996) indicated that, as the radiation sensitivity of $\mathrm{T}$ lymphocyte is different widely from that of red blood cells a high enough dose should be applied to destroy almost all the T lymphocytes while causing as little as possible damage to the red cells (12-15). Recent studies indicate that doses higher than $30 \mathrm{~Gy}$, are required ${ }^{(16)}$. Since it causes only minor changes in the concentration of the essential constituents of the red cells, e.g. ATP, biophosphoglyceric (DPG) catalase, glutathione peroxides and superoxidedismutase (SOD). However, these higher doses cause potassium leakage from the red blood cells which is attributed to the damage occurred in the cell membrane. In the range of doses used (10-30) Gy, the effect of irradiation when RBCs are stored at $4{ }^{\circ} \mathrm{C}$ is to promote a balanced passive exchange of intracellular Potassium (K) for extra cellular Sodium ( $\mathrm{Na}$ ); this exchange does not affect the volume of the RBCs ${ }^{(9)}$. Radiation damage to RBCs occurs as the hydroxyl $(\mathrm{OH})$ radicals can react with other cellular components in addition to the target molecule.

The aim of this study was to investigate the effects of gamma radiation, ascorbic acid (vitamin c) added in small concentrations, and the combined effect of both on the lifespan of erythrocytes through determining RBCs hemolysis for conserving it as long as possible without any change in erythrocytes biophysical properties.

\section{Methods}

A volume of $2.9 \mathrm{ml}$ of blood was drawn from 10 healthy volunteers ( 5 males and 5 females) with ages between $30-40$ years and collected in EDTA tubes.

\section{Gamma irradiation}

Blood samples were exposed to different doses of gamma radiation (1, 5, 10, 20 and $30 \mathrm{~Gy})$ and stored at $4{ }^{\circ} \mathrm{C}$. Gamma source was standard from 137Cs source (0.66) MeV (model GB-150 type $\mathrm{B})$. The exposure rate of $0.34 \mathrm{~Gy} / \mathrm{min}$. has been calibrated by standard ionization chamber type (NE-2571) of volume $0.06 \mathrm{cc}$ with air kerma, Calibration factor NK=41.0+0.25 $\mathrm{mGy} / \mathrm{min}$. measured by electrometer type NE2571/1 manufactured by nuclear enter press 
Ltd in UK. The value of absorbance (RBCs hemolysis) was recorded for each dose and repeated weekly up to 10 weeks.

\section{Adding ascorbic acid}

$0.1 \mathrm{ml}$ of ascorbic acid with different concentrations $(1,3,5,7$, and 10) $\mu \mathrm{M}$ of ascorbic acid was added to $2.9 \mathrm{ml}$ of blood and stored at $4{ }^{\circ} \mathrm{C}$. Each week $0.05 \mathrm{ml}$ of blood was added to $9 \mathrm{ml}$ of $\mathrm{NaCl}$ saline in a tube then $3 \mathrm{~mL}$ from the suspension was taken in a standard curette of the spectrophotometer, after shacking gently and carefully the value of absorbance at $577 \mathrm{~nm}$ was recorded. This process was repeated each week up to ten weeks.

\section{Ascorbic acid with gamma irradiation}

Different concentrations of ascorbic acid (1, 3, and $5 \mu \mathrm{M}$ ) were added into different blood samples and exposed to $20 \mathrm{~Gy}$ of gamma radiation. Also, the two ( 7 and $10 \mu \mathrm{M})$ concentrations of ascorbic acid added in to another blood samples then exposed to $1 \mathrm{~Gy}$ of gamma radiation, the samples stored at $4{ }^{\circ} \mathrm{C}$ and examined for 10 weeks.

The data were recorded using spectrometer model JASCO (V-530), UV/VIS in Japan. The intensity of the peak at $577 \mathrm{~nm}$ of absorbance spectrum represented the degree of hemoglobin breakdown (degree of hemolysis) (17).

\section{Statistical analysis}

The results were presented as mean \pm Standard deviation (SD) of percentage and statistical analysis were performed using students t-test (paired and unpaired two tailed) taking ( $p<$ 0.01 ) as the significance.

\section{Results}

Table (1) shows the percentage of hemolysis of RBCs in the case of control (without irradiation or adding the ascorbic acid) through 10 weeks; in this case we observed that the hemolysis increased as the storage time increased.

Table 1. The relation between absorbance values (RBC hemolysis) for control samples and storage times through 10 weeks at $4{ }^{\circ} \mathrm{C}$

\begin{tabular}{cc}
\hline Storage time in weeks & Percentages of RBC hemolysis \pm SD \\
\hline 1 & $7.0 \pm 1.49$ \\
2 & $13.0 \pm 1.34$ \\
3 & $18.5 \pm 1.49$ \\
4 & $25.0 \pm 1.49$ \\
5 & $33.8 \pm 1.55$ \\
6 & $39.0 \pm 1.49$ \\
7 & $44.9 \pm 1.17$ \\
8 & $50.2 \pm 1.49$ \\
9 & $56.3 \pm 1.20$ \\
10 & $63.7 \pm 1.63$ \\
\hline
\end{tabular}

The effect of different doses of gamma radiation $(1,5,10,20$, and 30$)$ Gy on the RBCs hemolysis of the blood samples are shown in table (2). It was found that irradiation of the blood samples increased RBCs hemolysis, which was undesirable, but with increasing the storage time the rate of the hemolysis decreased in all samples exposed to gamma radiation compared with the controls. It was observed that $25 \%$ of RBCs hemolysis occurred after irradiation with 5 Gy during the fifth week, while in un-irradiated sample $33.8 \%$ of RBCs hemolysis occurred during the fifth week, the difference was significant $(p<0.01)$ between them. 
Table 2. The relation between RBC hemolysis for blood samples exposed to different doses of gamma radiation and stored at $4{ }^{\circ} \mathrm{C}$ through 10 weeks

\begin{tabular}{cccccccccccc}
\hline $\begin{array}{c}\text { Gamma } \\
\begin{array}{c}\text { radiation dose } \\
\text { Gy }\end{array}\end{array}$ & $\mathbf{1}$ & $\mathbf{2}$ & $\mathbf{3}$ & $\mathbf{4}$ & $\mathbf{5}$ & $\mathbf{6}$ & $\mathbf{7}$ & $\mathbf{8}$ & $\mathbf{9}$ & $\mathbf{1 0}$ \\
\hline \multirow{2}{*}{1} & $4.0 \pm$ & $8.0 \pm 1$ & $13.0 \pm$ & $16.0 \pm$ & $20.0 \pm$ & $23.9 \pm$ & $27.6 \pm$ & $30.0 \pm$ & $32.4 \pm$ & $34.7 \pm$ \\
& 1.22 & .26 & 1.56 & 1.67 & 1.58 & 1.25 & 1.42 & 1.43 & 1.67 & 1.37 \\
\hline \multirow{2}{*}{5} & $6.4 \pm$ & $9.2 \pm$ & $15.0 \pm$ & $21.2 \pm$ & $25.0 \pm$ & $29.5 \pm$ & $33.0 \pm$ & $36.3 \pm$ & $38.2 \pm$ & $41.1 \pm$ \\
& 1.19 & 1.11 & 1.21 & 1.56 & 1.87 & 1.73 & 1.63 & 1.69 & 1.72 & 1.24 \\
\hline \multirow{2}{*}{10} & $6.8 \pm$ & $10.0 \pm$ & $15.9 \pm$ & $22.5 \pm$ & $26.0 \pm$ & $31.0 \pm$ & $34.7 \pm$ & $38.0 \pm$ & $41.2 \pm$ & $43.4 \pm$ \\
& 1.33 & 1.55 & 1.48 & 1.59 & 1.23 & 1.20 & 1.31 & 1.40 & 1.73 & 1.82 \\
\hline \multirow{2}{*}{20} & $7.2 \pm$ & $12.0 \pm$ & $17.3 \pm$ & $24.0 \pm$ & $27.5 \pm$ & $32.0 \pm$ & $35.4 \pm$ & $39.0 \pm$ & $42.2 \pm$ & $45.0 \pm$ \\
& 1.87 & 1.17 & 1.28 & 1.51 & 1.29 & 1.62 & 1.77 & 1.30 & 1.14 & 1.32 \\
\hline \multirow{2}{*}{30} & $7.5 \pm$ & $13.5 \pm$ & $19.0 \pm$ & $25.0 \pm$ & $28.9 \pm$ & $34.0 \pm$ & $37.2 \pm$ & $41.8 \pm$ & $44.9 \pm$ & $47.8 \pm$ \\
& 1.15 & 1.43 & 1.23 & 1.49 & 1.54 & 1.17 & 1.40 & 1.53 & 1.61 & 1.31 \\
\hline
\end{tabular}

The results of the blood samples treated with different ascorbic acid concentrations $(1,3,5,7$ and 10) $\mu \mathrm{M}$ are shown in table (3). The results showed that $25 \%$ of RBCs hemolysis started after $7^{\text {th }}$ week while in untreated one RBCs hemolysis reaches $25 \%$ after 4 th week only. $25 \%$ of RBCs hemolysis for $10 \mu \mathrm{M}$ of ascorbic acid concentration started after 7th week while for control started after $4^{\text {th }}$ week, this difference was significant $(p<0.01)$.

Table 3. The relation between RBC hemolysis for blood samples treated with different concentrations of ascorbic acid and storage times through 10 weeks at $4{ }^{\circ} \mathrm{C}$

\begin{tabular}{cccccccccccc}
\hline $\begin{array}{c}\text { concentrations } \\
\text { of ascorbic } \\
\text { acid } \boldsymbol{\mu M}\end{array}$ & $\mathbf{1}$ & $\mathbf{2}$ & $\mathbf{3}$ & $\mathbf{4}$ & $\mathbf{5}$ & $\mathbf{6}$ & $\mathbf{7}$ & $\mathbf{8}$ & $\mathbf{9}$ & $\mathbf{1 0}$ \\
\hline 1 & $1.0 \pm$ & $2.0 \pm$ & $3.0 \pm$ & $4.3 \pm$ & $5.7 \pm$ & $8.0 \pm$ & $10.0 \pm$ & $12.0 \pm$ & $14.2 \pm$ & $16.7 \pm$ \\
& 1.23 & 1.34 & 1.40 & 1.28 & 1.32 & 1.65 & 1.54 & 1.48 & 1.39 & 1.46 \\
\hline 3 & $1.3 \pm$ & $2.6 \pm$ & $4.2 \pm$ & $6.3 \pm$ & $8.4 \pm$ & $10.0 \pm$ & $13.0 \pm$ & $15.3 \pm$ & $18.0 \pm$ & $21.3 \pm$ \\
& 1.26 & 1.87 & 1.94 & 1.82 & 1.25 & 1.67 & 1.97 & 1.60 & 1.59 & 1.33 \\
\hline \multirow{2}{*}{5} & $1.9 \pm$ & $3.0 \pm$ & $7.0 \pm 1$ & $11.6 \pm$ & $14.0 \pm$ & $17.0 \pm$ & $19.4 \pm$ & $21.9 \pm$ & $23.0 \pm$ & $25.0 \pm$ \\
& 1.11 & 1.19 & .61 & 1.75 & 1.83 & 1.54 & 1.20 & 1.16 & 1.22 & 1.43 \\
\hline 7 & $4.0 \pm$ & $9.8 \pm$ & $12.0 \pm$ & $15.2 \pm$ & $17.7 \pm$ & $20.1 \pm$ & $22.5 \pm$ & $25.0 \pm$ & $27.2 \pm$ & $29.5 \pm$ \\
& 1.19 & 1.41 & 1.49 & 1.62 & 1.58 & 1.67 & 1.92 & 1.44 & 1.88 & 1.73 \\
\hline \multirow{2}{*}{10} & $5.2 \pm$ & $10.4 \pm$ & $13.7 \pm$ & $17.2 \pm$ & $20.4 \pm$ & $22.9 \pm$ & $25.0 \pm$ & $27.0 \pm$ & $29.3 \pm$ & $33.0 \pm$ \\
& 1.13 & 1.56 & 1.37 & 1.47 & 1.73 & 1.94 & 1.76 & 1.57 & 1.53 & 1.82 \\
\hline
\end{tabular}


The changes in percentages of RBCs hemolysis with respect to the storage time (through 10 weeks) were studied for blood samples pretreated with (1,3 and 5) $\mu \mathrm{M}$ and (7 and 10) $\mu \mathrm{M}$ then irradiated with 20 Gy and 1 Gy respectively, the results are shown in tables (4 and5). In pre-treated with $(1,3$ and 5) $\mu \mathrm{M}$ concentrations of ascorbic acid then irradiated to $20 \mathrm{~Gy}$, we observed that $25 \%$ of RBCs hemolysis for $3 \mu \mathrm{M}$ concentration of ascorbic acid started at 5 th week while for $1 \mu \mathrm{M}$ this ratio of hemolysis started between 6th and 7th weeks as shown in table (4).

Table 4. The relation between percentages of RBC hemolysis for blood samples treated with low ascorbic acid concentrations then exposed to $20 \mathrm{~Gy}$ dose of gamma radiation and storage times through 10 weeks at $4{ }^{\circ} \mathrm{C}$

\begin{tabular}{cccccccccccc}
\hline $\begin{array}{c}\text { Blood samples } \\
\text { treated with } \\
\text { ascorbic acid } \\
\text { and exposed } \\
\text { to 20 G }\end{array}$ & $\mathbf{1}$ & $\mathbf{2}$ & $\mathbf{3}$ & $\mathbf{4}$ & $\mathbf{5}$ & $\mathbf{6}$ & $\mathbf{7}$ & $\mathbf{8}$ & $\mathbf{9}$ & 10 \\
\hline 1 & $3.0 \pm$ & $7.9 \pm$ & $14.0 \pm$ & $17.5 \pm$ & $20.4 \pm$ & $23.8 \pm$ & $27.6 \pm$ & $30.0 \pm$ & $32.2 \pm$ & $33.2 \pm$ \\
\hline 3 & 1.23 & 1.1 & 1.24 & 1.26 & 1.38 & 1.57 & 1.68 & 1.75 & 1.89 & 1.66 \\
\hline \multirow{2}{*}{3} & $4.8 \pm$ & $9.6 \pm 1$ & $14.4 \pm$ & $20.2 \pm$ & $25.0 \pm$ & $27.5 \pm$ & $30.0 \pm$ & $33.3 \pm$ & $35.2 \pm$ & $36.8 \pm$ \\
& 1.23 & .45 & 1.34 & 1.33 & 1.67 & 1.42 & 1.56 & 1.38 & 1.74 & 1.56 \\
\hline & $6.7 \pm$ & $10.0 \pm$ & $15.2 \pm$ & $21.5 \pm$ & $26.0 \pm$ & $28.9 \pm$ & $31.7 \pm$ & $34.5 \pm$ & $36.2 \pm$ & $38.4 \pm$ \\
& 1.21 & 1.35 & 1.60 & 1.43 & 1.49 & 1.65 & 1.23 & 1.72 & 1.56 & 1.29 \\
\hline
\end{tabular}

The minimum rates of RBCs hemolysis observed in samples which pre-treated with (7 and 10) $\mu \mathrm{M}$ concentrations of ascorbic acid then irradiated with $1 \mathrm{~Gy}$ as shown in table (5), in this case $25 \%$ of RBCs hemolysis started at $9^{\text {th }}$ week.

Table 5. The relation between percentages of RBC hemolysis for blood samples treated with different high ascorbic acid concentrations then exposed to $1 \mathrm{~Gy}$ dose of gamma radiation and storage times through weeks at $4{ }^{\circ} \mathrm{C}$

\begin{tabular}{cccccccccccc}
\hline $\begin{array}{c}\text { Blood samples } \\
\text { treated with a } \\
\text { ascorbic acid } \\
\text { and exposed } \\
\text { to } 1 \text { Gy }\end{array}$ & $\mathbf{1}$ & $\mathbf{2}$ & $\mathbf{3}$ & $\mathbf{4}$ & $\mathbf{5}$ & $\mathbf{6}$ & $\mathbf{7}$ & $\mathbf{8}$ & $\mathbf{9}$ & $\mathbf{1 0}$ \\
\hline 7 & $2.3 \pm$ & $5.5 \pm$ & $7.8 \pm$ & $12.0 \pm$ & $15.5 \pm$ & $18.4 \pm$ & $20.0 \pm$ & $22.0 \pm$ & $24.0 \pm$ & $26.5 \pm$ \\
& 1.31 & 1.82 & 1.32 & 1.59 & 1.42 & 1.63 & 1.49 & 1.24 & 1.28 & 1.26 \\
\hline 10 & $1.8 \pm$ & $4.0 \pm$ & $6.2 \pm$ & $10.0 \pm$ & $13.0 \pm$ & $15.5 \pm$ & $17.6 \pm$ & $20.0 \pm$ & $22.0 \pm$ & $24.0 \pm$ \\
& 1.16 & 1.22 & 1.43 & 1.38 & 1.12 & 1.29 & 1.61 & 1.52 & 1.18 & 1.38 \\
\hline
\end{tabular}




\section{Discussion}

The validity of stored blood has been investigated by different studies and the current study was done to show the effects of gamma radiation, ascorbic acid added in small concentrations, and the combined effect of both on the lifespan of erythrocytes through determining RBCs hemolysis for conserving it as long as possible without any change in erythrocytes biophysical properties. As shown in table (1), the percentage of hemolysis of RBCs in the case of control increased as the storage time increased through 10 weeks due to the elevation of lipid peroxidation and hemoglobin oxidation (8) and extracellular potassium (K) concentration in red blood cells storage ${ }^{(18)}$. In irradiation of blood samples to different doses of gamma radiation $(1,5,10,20$, and 30) Gy, it was found that RBCs hemolysis increased but with increasing the storage time the rate of the hemolysis decreased in all samples compared with the controls. During the fifth week, it was observed that $25 \%$ and $33.8 \%$ of RBCs hemolysis occurred after irradiation with $5 G y$ and in un-irradiated sample respectively, and the difference was significant $(p<0.01)$ between them as shown in table (2). Mintz and Anderson (1993) found that the mean Potassium (k) and hemoglobin ( $\mathrm{Hb})$ concentration at the end of 35 days of storage for both the irradiated group ( $30 \mathrm{~Gy}$ ) and the unirradiated one were not significantly different (19).

Treated the blood samples with different ascorbic acid concentrations (1, 3, 5, 7 and 10) $\mu \mathrm{M}$ showed the role of antioxidant effect of ascorbic acid which increased with increasing the concentrations up to $10 \mu \mathrm{M}$. Results of this study match the results that by Lenton et al (2003), who affirmed that ascorbic acid plays a vital and central role in the defense against free radicals and oxidants that are implicated in chronic diseases ${ }^{(20)}$.

Different effects were obtained in pre-treated with of ascorbic acid then irradiated to gamma ray. The minimum rates of RBCs hemolysis observed in samples which pre-treat high concentrations of ascorbic acid then irradiated with $1 \mathrm{~Gy}$. The results indicated that with increasing ascorbic acid concentration low dose of gamma radiation required to obtain minimum RBCs hemolysis.

The obtained results indicated that irradiation of human blood with a certain doses of gamma ray, treated with small concentration of ascorbic acid or both, the two factors together can protect RBCs of blood from hemolysis for a longer time. The minimum rate of $\mathrm{RBCs}$ hemolysis was observed for $10 \mu \mathrm{M}$ ascorbic acid concentration with irradiation to $1 \mathrm{~Gy}$ of gamma ray. We observed when the concentration of the ascorbic acid in blood samples increased; low levels of gamma irradiation were added to obtain the minimum RBCs hemolysis.

\section{Acknowledgments}

The authors would like to thank General Kirkuk Hospital and Faculty of Pure Science at Tikrit University for their help and facilities.

\section{Author contribution}

Dr. Faraj: writing the article with resolving the data. Abdullah and Dr. Muhammad performed the practical part of the work.

\section{Conflict of interest}

None.

\section{Funding}

personal funding.

\section{References}

1. Veale MF, Healey G, Sparrow RL. Effect of additive solutions on red blood cell (RBC) membrane properties of stored RBCs prepared from whole blood held for 24 hours at room temperature. Transfusion. 2011; 51 Suppl 1: 25S-33S. doi: 10.1111/j.15372995.2010.02960.x.

2. Murray RK, Bender DA, Botham KM, et al. Harper's illustrated biochemistry. $28^{\text {th }}$ ed. The McGraw-Hill Companies; 2009.

3. Ali FM, Elgebaly $\mathrm{RH}$, Kheder $\mathrm{MH}$, et al. Evaluation of the hazards associating injection of heart diseased patient with radiophrmaceuticals for imaging with gamma camera. Proceedings of seventh international symposium on change and continuity in radiation protection", Cardiff, UK, 2005.

4. Marjani A, Moradi A, Ghourcaie AB. Alterations in plasma lipid peroxidation and erythrocyte superoxide dismutase and glutathione peroxidase enzyme activities during storage of blood. Asian J Biochem. 2007; 2: 118-23. DOI: 10.3923/ajb.2007.118.123.

5. Huyut Z, Şekeroğlu MR, Balahoroğlu $R$, et al. The relationship of oxidation sensitivity of red blood cells 
and carbonic anhydrase activity in stored human blood: effect of certain phenolic compounds. Biomed Res Int. 2016; 2016(4): 1-8. doi: 10.1155/2016/3057384.

6. Lobo V, Patil A, Phatak A, et al. Free radicals, antioxidants and functional foods: Impact on human health. Pharmacogn Rev. 2010; 4: 118-26. doi: 10.4103/0973-7847.70902.

7. Moor GL, Ledoford ME. Effect of 4000 rad irradiation on the in vitro storage properties of packed red cell. Transfusion. 1985; 25(6): 583-5.

8. Anand AJ, Dzik WH, Imam A, et al. Radiation induced red cell damage; role of reactive oxygen species. Transfusion. 1997; 37: 160-5.

9. Brugnara C, Churchill WH. Effect of Irradiation on red cell cation content and transport. Transfusion. 1992; 32: $246-8$.

10. Moroff G, Leitman SF, Luban NL. Principles of blood irradiation dose validation and quality control. Transfusion. 1997; 37(10): 1084-92.

11. Jacob GB. A review on the effect of ionizing radiation on blood and blood components. Radiat Physics Chem. 1998; 53(5): 511-23.

12. Britten AJ. A method to evaluate intra-operative gamma probes for sentinel lymphatic node localization. Eur J Nucl Med. 1999; 26(2): 76-83.

13. Davey RJ, McCoy NC, Yu M, et al. The effect prestorage radiation on post transfusion red cell survival. Transfusion. 1992; 32(6): 525-8.
14. Pribush A, Agam G, Yermiahu T, et al. Radiation damage to the erythrocyte membrane the effect of medium and cell concentration. Free Radic Res. 1994; 21(3): 135-46.

15. Katz D, Mazor D, Dvilansky A, et al. Effect of radiation on Red blood cell membrane and intra cellular oxidative defense system. Free radiology Research. 1996; 24(3): 199-204.

16. Effects of ionizing radiations on blood and blood components: a survey, IAEA, Austria, 1997.

17. Goldberg B, Stern A. The role of superoxide anion as a toxic species in the erythrocyte. Arch Biochem Biophys. 1977; 178(1): 218-25.

18. Marnett $\sqcup$. Lipid peroxidiation-DNA damage by malondialdehde. Mutat Res. 1999; 424(1-2):83-95.

19. Mintz PD, Anderson G. Effect of gamma irradiation on the in vivo recovery of stored red blood cells. Ann Clin Lab Sci. 1993; 23(3): 216-20.

20. Lenton KJ, Sané AT, Therriault $H$, et al. Vitamin $C$ augments Lymphocytes glutathioue in subjects with ascorbic deficiency. Am J Clin Nutr. 2003; 77(1): 18995. doi: 10.1093/ajcn/77.1.189.

\section{Correspondence to Dr. Kharman A. Faraj \\ E-mail: kharman.faraj@univsul.edu.iq \\ Received Mar. $8^{\text {th }} 2018$ \\ Accepted Aug. $9^{\text {th }} 2018$}

